\title{
Warning signal termination does not function as a feedback signal
}

\author{
JOHN W. OWEN, ROBERT T. HERDEGEN, and GEORGE A. CICALA \\ University of Delaware, Newark, Delaware 19711
}

\begin{abstract}
Shuttle avoidance acquisition is most rapid when both warning signal termination (WST) and a feedback signal (FS) are made response contingent. A parsimonious interpretation, framed within attention theory, is that the presence of both response-contingent events increases the probability that the subject will attend to a reliable predictor of safety. This explanation was tested by eliminating WST and replacing it with either of two redundant FSs. Although these two experimental groups also contained two predictive events, this situation produced no facilitation over acquisition with a single FS. The combination of WST and an FS initially produced superior responding, but, as expected, the differences are attenuated later in training. These results were interpreted as indicating that WST and an FS serve different reinforcing functions.
\end{abstract}

The combination of warning signal termination (WST) and a feedback signal (FS) is usually more effective in reinforcing shuttle avoidance learning than either event alone. This was first demonstrated by Bolles and Grossen (1969), who provided an FS only on avoidance trials. More recently, Cicala and Owen (1976) confirmed this finding when the relevant stimulus changes were made contingent on both avoidance and escape responses throughout avoidance learning. They chose to interpret this result by specifying, consistent with the reasoning of Morris (1974), two different forms of fear reduction provided by WST and an FS. They suggested that WST following the occurrence of an instrumental response reinforces through fear dissipation, and that an FS following that response reinforces through the Pavlovian inhibition of fear. Thus, when both of these events occur following the instrumental response, greater reinforcement is achieved through the combination of these two forms of fear reduction.

Bolles and Grossen (1969) present a different view of the role of FSs in avoidance learning in that they assume that FSs and WST are effective reinforcers of avoidance behavior because they provide response feedback and predict a shock-free interval. These authors have not attempted to explain within that framework why two stimulus events, WST and an FS in combination, should more effectively reinforce avoidance learning than either event alone. An explanation of this phenomenon which appears consistent with Bolles and Grossen's position derives from attention theory (cf. Sutherland \& Mackintosh, 1971). These theories assume that redundant signals can be more effective in many learning situations because of the increased likelihood of attending to a

Requests for reprints should be sent to George A. Cicala, Department of Psychology, University of Delaware, Newark, Delaware 19711. John W. Owen is now at West Chester State College, West Chester, Pennsylvania. reliable predictor when two predictive stimuli are presented instead of one. This phenomenon, termed additivity of cues, has been demonstrated with several species in a variety of appetitive learning situations (Eninger, 1952; Kamin, 1969; Miles \& Jenkins, 1973; Warren, 1953), but not in aversive learning situations. If this reasoning is applied to the avoidance learning situation, combined WST and an FS may be more effective than either event alone, because when both are response contingent there is a greater likelihood of attending to a reliable predictor of an interval free from shock. This reasoning predicts that any facilitation produced by redundant cues should be most pronounced early in training since with extended training learning curves would be expected to converge.

The present experiment was conducted to determine if the addition of a second, redundant FS could enhance performance, producing a level of avoidance comparable to that resulting from simultaneous WST and FS onset. If the reinforcing effectiveness of WST is derived from its informational value, it seems reasonable to assume that a second FS can serve in its place. Three groups of rats were run to substantiate that a tone, a clicker, and the more commonly used period of darkness can each function as an effective FS when WST is delayed. Two additional groups received delayed WST and two FSs, either darkness plus tone or darkness plus clicker. The performance of these groups was compared to a group receiving response-contingent WST and a darkness FS. The present experiment did not specifically demonstrate the necessity of an FS in producing avoidance learning when WST is delayed, on the assumption that this had been previously well documented. Bower, Starr, and Lazarovitz (1965) and Kamin (1956) have shown that only low to moderate levels of avoidance performance obtain with delayed WST. Further, Bolles and Grossen (1969) have clearly shown that this decrement is overcome with the addition of an FS. 


\section{METHOD}

\section{Subjects}

Sixty male Wistar rats weighing about $250 \mathrm{~g}$ were used as subjects.

\begin{abstract}
Apparatus
The apparatus was a shuttlebox, $40 \times 17.5 \times 17.5 \mathrm{~cm}$, made of aluminum with a Plexiglas top. The floor of the chamber consisted of $.23-\mathrm{cm}$ steel rods on $1.25-\mathrm{cm}$ centers. Each half of the floor was a separately mounted section connected to a mercury switch, which permitted the location of the animal to be monitored by the electromechanical programming. The WS was white noise from a Grason-Stadler noise generator (Model 901), delivered to a speaker $27.5 \mathrm{~cm}$ above the shuttlebox. Situated next to the speaker were a $6-\mathrm{W}$ houselight, a $2,900-\mathrm{Hz}$ Sonalert tone generator, and a clicker. Each of the three auditory stimuli had an intensity of $81 \mathrm{~dB}$. The US was $90 \mathrm{~V}$ ac provided by a $150-\mathrm{k} \Omega$ fixed-impedance shock source (Campbell \& Masterson, 1969). The entire shuttle apparatus was contained in a sound-attenuating chamber.
\end{abstract}

\section{Procedure}

The subjects were divided into six groups of 10 rats each. All of the groups received 100 trials of shuttle avoidance with a 10 -sec WS-US interval and a 35-sec ITI. The groups differed in the type of response-contingent stimulus change. Following each escape or avoidance response, subjects in the darkness (D) group spent $10 \mathrm{sec}$ in the dark. For subjects in the WST-plus-darkness (WST + D) group, each response was followed by immediate termination of the WS and a 10-sec period of darkness. The stimuli used for these two groups were identical to those used by Cicala and Owen (1976) in demonstrating the superiority of WST with an FS over an FS superimposed on the WS. For subjects in two additional groups, each response was followed by two FSs which coexisted and coterminated with the WS. These groups received either darkness plus a tone $(D+T)$ or darkness plus a clicker $(D+C)$. After the data from these groups were collected, two additional groups were run which received delayed WST. Subjects in the tone (T) group received a 10-sec response-contingent tone, and subjects in the clicker (C) group received a 10 -sec clicker.

\section{RESULTS AND DISCUSSION}

The results of this experiment are presented in Figure 1, which shows mean percent avoidance throughout acquisition. Inspection of this figure suggests that, while all groups seem to have acquired the response, the WST $+D$ group appears to attain superior avoidance early in training. To provide an assessment of these early and late effects, an analysis of variance was performed on the number of avoidances in each block of 50 trials, with blocks treated as a repeated measure. This test indicated significant differences for groups $[F(5,54)=3.85, \mathrm{p}<.005]$, trial blocks $[\mathrm{F}(1,54)=$ $76.74, p<.001]$, and for the interaction $[F(5,54)=$ $2.39, p<.05]$. A subsequent Newman-Keuls test performed on the interaction indicated that during the first 50 trials the performance of Group WST + D was superior to that of the other five groups, among which there were no differences. The only difference during the last 50 trials was the superiority of Group WST + D over Group T.

The data of this experiment indicate that darkness, a tone, and a clicker are all equally effective FSs. More

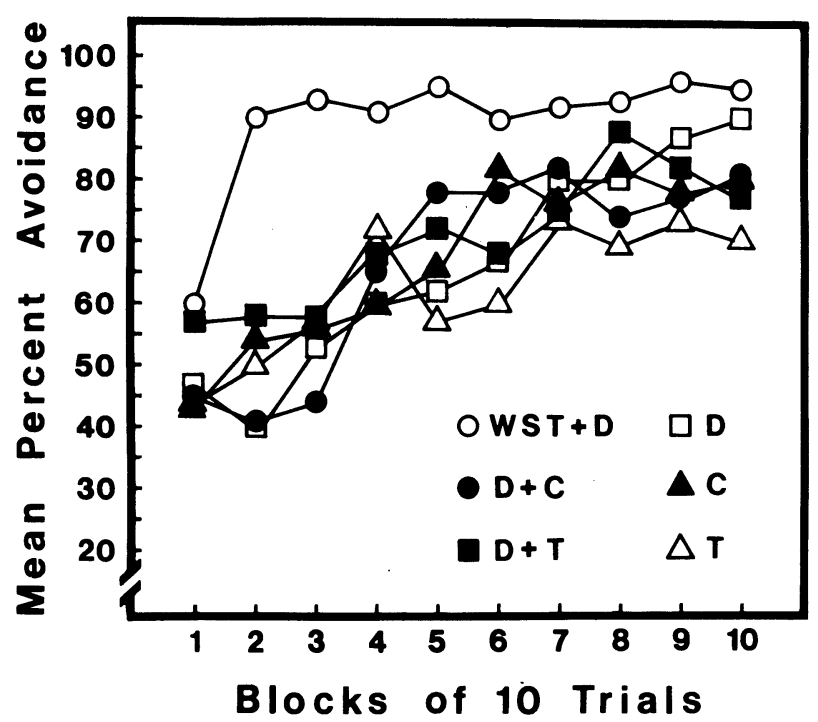

Figure 1. Mean percent avoidance as a function of blocks of 10 trials. Subjects received either one FS, two FSs, or WST plus an FS.

importantly, the early superiority of WST, combined with an FS over all the other reinforcing combinations, suggests that WST provides a source of reinforcement which is not provided by an FS. These results lend no support to the suggestion that an additional FS might serve to increase the likelihood of attending to a stimulus which reliably predicts a shock-free interval. This finding is consistent with both the theory and the data presented by Rescorla and Wagner (1972). Their model correctly predicts that two conditioned stimuli whose onset and offset are simultaneous can be no more reinforcing than a single stimulus occupying the same interval.

The fact that WST combined with an FS produced an initial superiority over two FSs indicates that both events were attended to early in learning. It should, perhaps, be pointed out that the predictions of attention theory (Sutherland \& Mackintosh, 1971) do not preclude early attention to two separate events. What they do preclude is the early, simultaneous attention to two redundant events. Since it is clear that WST and FSs differ in their functioning or in the information they provide, at least two types of explanations can be posited. One explanation, couched in cognitive, informational terms, would specify the unique information each event conveys and how this information can combine to become more reinforcing. An alternative approach, which we prefer, is to ascribe different reinforcing functions to each of these response-contingent events. Specifically, the data support a model of avoidance reinforcement which views WST as permitting the dissipation of fear and the onset of an FS as permitting conditioned inhibition of fear, a model which further suggests that the combination of these two events can be more reinforcing than either stimulus event alone. 


\section{REFERENCES}

Bolles, R. G., \& Grossen, N. W. Effects of an informational stimulus on the acquisition of avoidance behavior in rats. Journal of Comparative and Physiological Psychology, 1969, 68, 90-99.

Bower, G., Starr, R., \& Lazarovitz, L. Amount of response-produced change in the CS and avoidance learning. Journal of Comparative and Physiological Psychology, 1965, 59, 13-17.

Campbell, B. A., \& Masterson, F. A. Psychophysics of punishment. In B. A. Campbell \& R. M. Church (Eds.), Punishment and aversive behavior. New York: AppletonCentury-Crofts, 1969.

Cicala, G. A., \& Owen, J. W. Warning signal termination and a feedback signal may not serve the same function. Learning and Motivation, 1976, 7, 356-367.

ENINGER, M. U. Habit summation in a selective learning problem. Journal of Comparative and Physiological Psychology, 1952, 45, 604-608.

KAMIN, L. J. The effects of termination of the CS and avoidance of the US on avoidance learning. Journal of Comparative and Physiological Psychology, 1956, 49, 420-424.

Kamin, L. J. Predictability, surprise, attention, and conditioning. In B. A. Campbell \& R. M. Church (Eds.),
Punishment and aversive behavior. New York: AppletonCentury-Crofts, 1969.

Miles, C. G., \& Jenkins, H. M. Overshadowing in operant conditioning as a function of discriminability. Learning and Motivation, 1973, 4, 11-27.

MorRIs, R. G. M. Pavlovian conditioned inhibition of fear during shuttle avoidance behavior. Learning and Motivation, 1974, 5, 424-447.

Rescorla, R. A., \& WAGNER, A. R. A theory of Pavlovian conditioning: Variations in the effectiveness of reinforcement and nonreinforcement. In A. H. Black \& W. F. Prokasy (Eds.), Classical conditioning II: Current research and theory. New York: Appleton-Century-Crofts, 1972.

Sutherland, N. S., \& MaCkintosh, N. J. Mechanisms of animal discrimination learning. New York: Academic Press, 1971.

WARREN, J. M. Additivity of cues in visual pattern discriminations by monkeys. Journal of Comparative and Physiological Psychology, 1953, 46, 484-486.

(Received for publication May $31,1977$. 